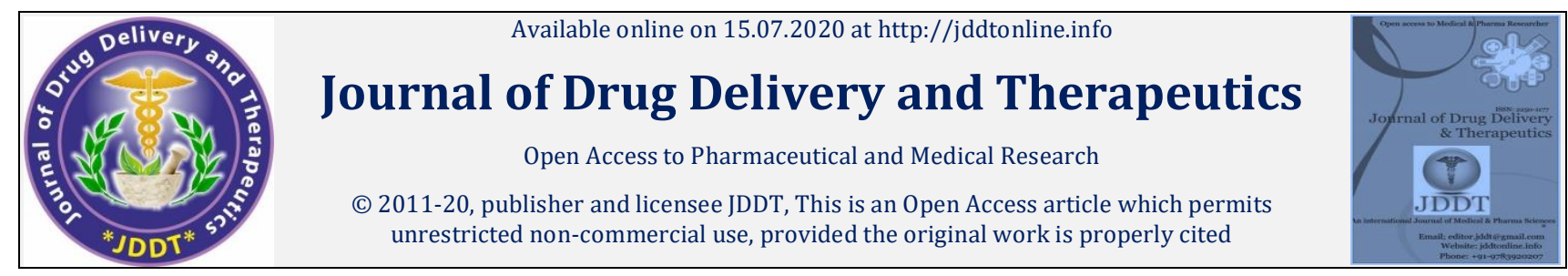

Open $\odot$ Access

Research Article

\title{
Evaluation of Anthelmentic and Antimicrobial Activity of the Extract of the Root of the Plant Jasminum multiflorum(Andr.)
}

\author{
Pahari S.K.*1, Gupta B.K. ${ }^{2}$, Debnath R. ${ }^{2}$, Das A. ${ }^{2}$ \\ ${ }^{1}$ Calcutta Institute of Pharmaceutical Technology and AHS, Banitabla, Uluberia, Howrah, West Bengal, India \\ ${ }^{2}$ Bharat Technology, Banitabla, Uluberia, Howrah, West Bengal, India
}

\begin{abstract}
As per qualitative evaluation in different solvents of the root of the plant satisfies the presence of cardiac glycosides along with trace quantities of steroid and saponins. Among them the petroleum ether extract of the root of the plant Jasminum multiflorum was evaluated for anthelmintic activity and the ethanolic extract was evaluated for antimicrobial activity. ${ }^{1,2}$ Traditionally this species are used in indolent ulcer, pitta and inflammation. Only few CNS activity are reported on ethanolic extract of aerial part of the plant, though the root of the plant is more potent as per folkore claim. The petroleum ether extract was investigated for anthelmentic activity using earthworm (Pheretima posthuma) at different concentration $(5 \mathrm{mg} / \mathrm{ml}-50 \mathrm{mg} / \mathrm{ml})$. As standard albendazole suspension $(10 \mathrm{mg} / \mathrm{ml})$ and $3 \%$ solution of normal saline was used as control. The death and paralysis time were recorded and compared. Extract exhibit significant anthelmentic activity at (100mg/ml) concentration and found effective.1,3,4 The ethanolic fraction of the root of the plant was collected and evaporated to dryness under vacuum to avoid the presence of even less quantity of ethanol in the extract. Two Gram ( ${ }^{+} \mathrm{ve}$ ) bacteria namely Bacillius subtilis, Staphylococcus aureus and two Gram (-ve) ve bacteria namely Escherichia coli and Klebsiella pneumonia were selected for the estimation of antimicrobial activity depending on zone of inhibition. It was seen that $100 \mathrm{mg} / \mathrm{ml}$ concentration of the extract showed maximum activity against Klebsiella pneumonia with a zone of inhibition $0.5 \mathrm{~mm}$ and for others it ranged from 0.3 to $0.4 \mathrm{~mm} .1,4,5$
\end{abstract}

Keywords: Jasminum multiforum; anthelmintic; antimicrobial; zone of inhibition

Article Info: Received 19 August 2019; Review Completed 12 April 2020; Accepted 07 May $2020 ; \quad$ Available online 15 July 2020

Cite this article as:

Pahari SK, Gupta BK, Debnath R, Das A, Evaluation of Anthelmentic and Antimicrobial Activity of the Extract of the Root of the Plant Jasminum multiflorum(Andr.), Journal of Drug Delivery and Therapeutics. 2020; 10(4):157-160

http://dx.doi.org/10.22270/jddt.v10i4.4219

*Address for Correspondence:

Pahari S.K., Calcutta Institute of Pharmaceutical Technology and AHS, Banitabla, Uluberia, Howrah, West Bengal, India

\section{INTRODUCTION}

'Worm' is a term which comes from a Greek word to describe 'Helminth'. Both tropical and sub-tropical countries are mainly affected by the intestinal worm \& different strategies are targeted officially. Among the huge population of world, majority of them are being suffered by this intestinal infection. The gastro intestinal agent is being resistant when exposed to the drug from synthetic origin for which focus has been given to control such infection by the agent obtained from natural sources. As per WHO, about 2 billion people are going to suffer for parasite infection in near future (2025). Not only are that, in developing countries, there are $57 \%$ of population are suffering from such infection. Nausea, vomiting, diarrhoea, abdominal pain is the general symptoms occur due to such infections. Though such reported data reveals the severity of such infection; Very little research work has been occurring to control such worms. Not only that, the evaluation of highly effective agent is very less also.
The major route of pathogenic process of such worms occurs mainly through food.5,6

There is an essential need to establish new drug molecule in this aspect because of the resistant is being developing by the worm to synthetic agent. Now to promote traditionally used anthelmintic plant, proper study and evolution of active principle from that source are needed. In this research, the petroleum ether fraction of the root of the plant J. multiforum was evaluated to identify the potentiality of the plant in this aspect. $5,6,7$

Infection procedure of round worm may be described by the following figure.

\section{Types of Worms}

The tropical and sub-tropical countries are severely infected by mainly three types of worm, namely, Tape-worm (cestodes), Round-worm (nematodes) and flukes (trematodes). 


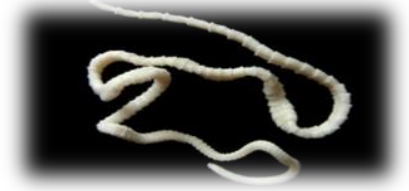

Tapeworms

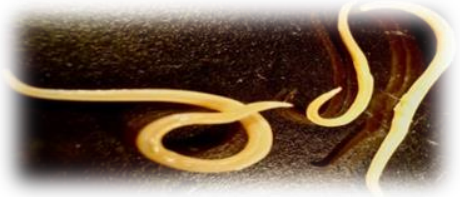

Round-worm

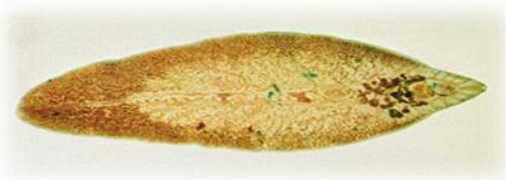

Flukes

\section{Classification of the Agent}

According to the similar types of chemical structure \& mechanism of action, the different anthelmintic agents are $7,10:-$
A. Benzimidazole derivatives: Since 1960, this is used. (Example. Mebendazole, Albendazole)
B. Diethycarbamazine: Since 1940, this is used.
C. Piperazine citrate: Applied to children
D. Praziaquantel: Derivative of Isoquinoline

\section{MATERIALS AND METHOD}

As per the literature survey different portion of different plants were successfully evaluated for anthelmentic activity. Not only that the aerial parts of Jasminum multiflorum showed anthelmintic activity in dose dependent manner8,9.

The worm Pheretima posthuma resembles with worm of human, helminthic infestation and their control. As per folklore claim the plant may be used of the treatment of helminthic infestation in human.

So I have selected the study to observe the action of petroleum ether extract of the root of the plant on Pheritima posthuma in varying dose dependent manner.
The petroleum ether extract of the roots of the plant is evaluated for its anthelmintic activity the preparation, collection and extraction and the percentage of yield of petroleum ether extract of Jasminum multiflorum was 0.14, respectively to dried starting materials. Evaluation of anthelmintic activities: Anthelmintic activities were evaluated for petroleum ether extract of Jasminum multiflorum.

As Pheritima posthuma possess similar morphological properties with intestinal round worm so it is selected for the study. It is collected from the horticulture department of Kolkata. The worm which were selected that is of $8 \pm 1 \mathrm{~cm}$. then these worms were divided into 5 groups namely control, standard and test extract $\left(\mathrm{T}_{1}, \mathrm{~T}_{2}, \mathrm{~T}_{3}\right)$ and each group contains 3 worms. The worms of control group were treated with 5\% Tween 60 in normal saline, for standard Albendazole $(10 \mathrm{mg} / \mathrm{ml})$ was taken and for test group petroleum ether extract of the root of Jasminum multiflorum $(5,10,25$ and $50 \mathrm{mg} / \mathrm{ml})$ in normal saline containing $5 \%$ of Tween 60 were taken. After that for the next 4hours they were observed for paralysis and death and the results is given in observation table.

Table 1:

\begin{tabular}{|l|l|l|l|l|}
\hline \multicolumn{2}{|l|}{ Types of dose } & No of worms & Time interval for paralysis & Time interval for death \\
\hline Control & $5 \%$ tween 60 in normal saline & 3 & - & - \\
\hline Standard & $\begin{array}{l}\text { Albendazole } \\
10 \mathrm{mg} / \mathrm{ml}\end{array}$ & 3 & $17 \pm 1.00$ & $39 \pm 0.70$ \\
\hline \multirow{3}{*}{ Test } & $5 \mathrm{mg} / \mathrm{ml}$ & 3 & $91 \pm 1.73$ & $148 \pm 2.64$ \\
\cline { 2 - 5 } & $10 \mathrm{mg} / \mathrm{ml}$ & 3 & $65.66 \pm 1.55$ & $128.33 \pm 1.52$ \\
\cline { 2 - 5 } & $25 \mathrm{mg} / \mathrm{ml}$ & 3 & $36 \pm 1.51$ & $63 \pm 2.07$ \\
\cline { 2 - 5 } & $50 \mathrm{mg} / \mathrm{ml}$ & 3 & $24 \pm 0.93$ & $50 \pm 2.08$ \\
\hline
\end{tabular}

\section{Evaluation of Antimicrobial Activity}

Though the medicines from synthetic sources are mainly screened for antimicrobial property; Now-a-days screening of natural products for such activity is being done in several cases. Although the scope of administration of medicine directly from extract of different plant material are not accepted. But in near future, by the application of more advanced technique, use of such natural product may takes place. The agent which is useful to stop growth or to kill the microorganism is commonly known as antibacterial agent \& importantly such agents are grouped according to the microorganism against which they shows the activity. Just like, antibiotics are effective against bacteria while antifungals are effective against fungi. The non-selective antimicrobials are known as disinfectant, while the purpose to prevent infection by the utilization of antimicrobial drug which is termed as antimicrobial prophylaxis. Though there are some difficulties during such screening like hydrophobicity of essential oil, or diffusion of lipophilic oil components through Agar. Among the different procedures, Nutrient agar used for such study \& screening obeyed Disk diffusion method. This research work is mainly done to observe whether the ethanolic extract of the root of $J$. multiflorumis shown any activity against bacteria or not \& here the zone of inhibition of bacteria were observed only. ${ }^{11,12}$

\subsection{Experimental}

Collection and recognition of the root of J. multiflorum; as described previously (In introductory chapter) it was done.

\subsection{Preparation of Plant Extract}

At first the plants were gathered from different locations of Kolkata and North 24 parganas in the month of July and August 2015

The roots of the plant were cut and collected after proper washing under constant tap water in the laboratory. Then 
the roots were subjected to air dry under shade condition for next one week. Then the roots were grinded and powdered. Then the powder was sieved through mesh no. 40 then the different extract was subjected for the different experimental work. In current evaluation the ethanolic extract was subjected to dryness to avoid the presence of trace quantity of alcohol and subjected for the evaluation of antimicrobial activity. 14,16

\subsection{Microorganism Taken}

The strains were taken from the School of Environmental Studies, Jadavpur University. The stock culture was maintained on nutrient agar media at $37^{\circ} \mathrm{C}$. and those microorganisms were used in the study.

\section{Agar Dilution Method for Microorganism}

1. For $30 \mathrm{mins}$ allow $20 \mathrm{ml}$ nutrient agar plates to dry at $37^{\circ} \mathrm{C}$.

2. By using sterile glass spreader, spread $500 \mu \mathrm{L}$ natural selected extract product on to the top of the agar by using pipette.

3. The plate was dried at room temperature for $30 \mathrm{mins}$.

4. Spread $500 \mu \mathrm{L}$ of the selected bacteria and was put on the extracted solution treated with nutrient agar plate.

5. Incubate the plates over night at $37^{\circ} \mathrm{C}$ and count the bacterial colonies. The agar absorption assay produces the latest consistent and irreproducible result.

6. Overlay $5 \mathrm{ml}$ agar containing $2 \%$ extracted solution, with and without $0.02 \%$ tween 80 , on $15 \mathrm{ml}$ of molten nutrient agar plates.

7. At $37^{\circ} \mathrm{C}$ the bacteria was incubated at the surface of agar plate and allowed for producing the colony.

8. Bacterial growth is measured taking 0 as standard corresponding to the growth of the plates.

Incorporation of the extract into agar, in the presence or absence of tween 80, results in inconsistent growth of bacteria and therefore un-reproducible result.11,10

- Gram (+)ve bacteria - Bacilliussubtilis, Staphylococcus aureus.

- Gram (-)ve bacteria - Escherichia coli, Klebsiella pneumonia.

\subsection{Purification of cylinder (cups)}

Porcelain beads of uniform size were selected inspite of stainless steel on. Then these beads were boiled in concentrated $\mathrm{HCl}$ for $15 \mathrm{mins}$, followed by washing with distilled water. Then these are putted in crucible and warmed at $600 \mathrm{c}$ for $30 \mathrm{mins}$.

\subsection{Composition of culture media to study zone of inhibition}

Table 2: Composition of the moderate, Nutrient Agar

\begin{tabular}{|l|l|}
\hline Peptone & $5.0 \mathrm{gm}$ \\
\hline Sodium Chloride & $5.0 \mathrm{gm}$ \\
\hline Beef Extract & $1.5 \mathrm{gm}$ \\
\hline Yeast extract & $1.5 \mathrm{gm}$ \\
\hline Agar & $1.5 \mathrm{gm}$ \\
\hline Distilled water up to & $1000 \mathrm{ml}$ \\
\hline $\mathrm{pH}$ & $7.4 \pm 0.2$ \\
\hline
\end{tabular}

Nutrient broth was used for the preparation of inoculums of the bacteria and nutrient agar used for screening method Composition of the medium, Nutrient Agar ${ }^{14,16}$.

\subsection{For Zone of Inhibition}

- Laminar air flow chamber was first wiped properly with ethanol and then switched on the air flowing unit and UV light. After 2-3mins switched off the UV light.

- 24 cleaned and sterilized petri-dish were taken and kept under the laminar air flow chamber.

- Petri-dishes were noticed correspondingly to the microorganism and the concentration of the standard and test drugs.

- Then Antibiotic assay media no.1 was prepared (as per above mentioned procedure)

- $\quad 20 \mathrm{ml}$ of the media is put to each petri-dish and kept it for some time to solidify.

- $\quad$ After it gets solidified, four holes were bored (2 hole for standard drug concentration \& 2 hole for test drug concentration) in the solidified media by the help of borer in each 32 petri-dish.

- The sterilized cotton was taken and dipped into the nutrient broth containing microorganism ${ }^{16,19}$ (prepared previously).

- The wipe each media with cotton, dipped into the nutrient broth containing microorganism.

- After that standard and aqueous extract of variable concentration was poured into the respective holes.

- Then the petri-dish were covered and kept into the incubator for 24 hours at $37.5^{\circ} \mathrm{C}$.

- After 24 hours the petri-dish were taken out and the observation were done.

- For Ethanolic extract same experimental procedure was followed.

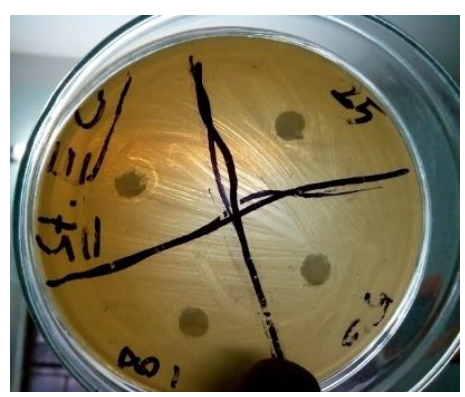

Figure 1:Bacillussubtilis

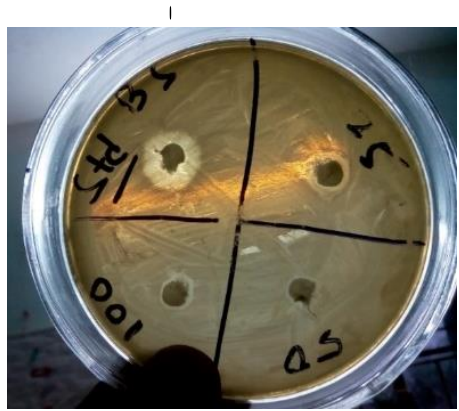

Figure 2: Escherichia coli 


\section{RESULTS AND CONCLUSION}

The different macerated extract in different solvents shows the presence of cardiac glycoside in polar solvent furthermore the plant material may be evaluated to observe the effect of cardiac glycoside as active constituents but in now the current research work was evaluated to observe anthelmintic activity of the root of the plant Jasminum multiflorum and the antimicrobial activity was evaluated for the ethanolic extract of the root of the plant Jasminum multiflorum.

The anthelmintic activity of the title compound on Pheritima posthuma is exhibited in the table given below. The data reveals that the roots of petroleum ether extract at the dose level of $5,10,25$ and $50 \mathrm{mg} / \mathrm{ml}$ showed significant anthelmintic activity compare to reference standard Albendazole. However petroleum ether extract of Jasminum multiflorum showed the effect at $50 \mathrm{mg} / \mathrm{ml}$ concentration about to comparable with the reference standard.

$100 \mathrm{mg} / \mathrm{ml}$ concentration of the drug has shown maximum activity against Klebsiella pneumonia whose zone of inhibition was $0.5 \mathrm{~mm}$. For others the zone of inhibition ranges from 0.4 to $0.3 \mathrm{~mm}$.

So finally the plant may be identified and evaluated for its folklore claim.

Table 3:

\begin{tabular}{|l|l|l|l|l|}
\hline Test Drug & $\begin{array}{l}\text { Staphylococcus } \\
\text { aureus }\end{array}$ & $\begin{array}{l}\text { Bacillus } \\
\text { subtilis }\end{array}$ & $\begin{array}{l}\text { Klebsiella } \\
\text { pneumonia }\end{array}$ & $\begin{array}{l}\text { Escherichia } \\
\text { coli }\end{array}$ \\
\hline Amoxicillin $(100 \mu \mathrm{g} / \mathrm{ml})$ & $0.3 \mathrm{~mm}$ & $0.5 \mathrm{~mm}$ & $0.2 \mathrm{~mm}$ & $0.4 \mathrm{~mm}$ \\
\hline J. multiflorum $(25 \mathrm{mg} / \mathrm{ml})$ & $0.2 \mathrm{~mm}$ & $0.2 \mathrm{~mm}$ & $0.2 \mathrm{~mm}$ & $0.3 \mathrm{~mm}$ \\
\hline J. multiflorum $(50 \mathrm{mg} / \mathrm{ml})$ & $0.2 \mathrm{~mm}$ & $0.2 \mathrm{~mm}$ & $0.4 \mathrm{~mm}$ & $0.3 \mathrm{~mm}$ \\
\hline J. multiflorum $(100 \mathrm{mg} / \mathrm{ml}$ & $0.4 \mathrm{~mm}$ & $0.3 \mathrm{~mm}$ & $0.5 \mathrm{~mm}$ & $0.4 \mathrm{~mm}$ \\
\hline Control & 00 & 00 & 00 & 00 \\
\hline
\end{tabular}

\section{ACKNOWLEDGEMENT}

As it is the part of the PhD work of the author, he is thankful to the principal of Calcutta Institute of Pharmaceutical Technology and AHS and the principal of Bharat Technology for providing the lab facility and permission to do the research work.

\section{REFERENCES}

1. Chopra R.N.;Nayer S.L.; Chopra I.C.;" Glossary of Indian Medicinal Plants"; CSIR; New Delhi; Edition-1992; 3;73.

2. Nadkarni K.M.; Nadkarni A.K.; "Indian MeteriaMedica”; "Popular Prakashan"; New Delhi; 2000; 1:363.

3. Anonymous;"The Wealth of India”; "A dictionary of Indian raw materials"; "Industrial Product"; "Publication and Information Directorate"; CSIR; New Delhi;1997; 5:284.

4. Kokate C.K.; PurohitA.K.;GokhaleS.B.; "History, definition and scope of Pharmacognosy"; 2005; 1-14.

5. Abraham M.;SaradadeviN.; ShelaR.; "Indian Journal of Medicinal Chemistry and Research"; 197; 69-88.

6. KalesarajR; KurupA; "Indian Journal of Pharmacy”; 1962; 69-88.

7. DashG.K.; MishraB.; Panda A.;Partro P.C.;Ganapathy G.; "Indian Journal of Natural Product"; 2003; 19-24.

8. Kuppasta I.J.; Nayak V.; "Indian Journal of Natural Product"; 2003; 19-27.

9. Bundy A.D.; "Immuno Epidemiology of Intestinal Helminthic Infection I"; "The Global Burden of Intestinal Nematode Disease; Trans Royal Society of Tropical Medical Hygiene"; 1994; 259261.

10. Sala A.V.; "Indian Medicinal Plants”; Orient Longman Pvt Ltd.; Chennai; 2002; 3:254.
11. Harder A.; Samson-Himmelstjerna V; “Cyclooctadepsipeptides- a new class of Anthelmintically Active Compounds". Parasitol; 2002; 481-488.

12. TaylorJ L.S.; RabeT.; McGaw L.J.; Jäger AK.; StadenJ.V.; "Antibacterial, Anthelmentic, and Antiamoebic activities in South African Plants"; Research Centre for Plant Growth and Development, School of Botany and Zoology, University of Natal Pietermaritzburg, Private Bag X01, Scottsville, 3209, South Africa; May 2001; 34(1):23-37.

13. BhangaleJ.; Patel R.; Acharya S.; Chaudhari K.; "Studies on Anti Inflammatory and Analgesic Activities of Jasminum sambac (L.) Aiton in Experimental Animal models, Am J. of Pharmtech. Res; 2012.

14. Sharma; Chandra S.S.; Rawat S.; Tomar A.; "Phytochemical study and antimicrobial activities of J. multiflorum", WJPPS, 2014; 3(4):735-742, ISSN- 2278-4357.

15. Gaud R.S.; Gupta G.D.; "A Text Book of Practical Microbiology"; NiraliPrakashan; New Delhi; $6^{\text {th }}$ edition. 2008, 4.1-4.4

16. Pal D.K.; Pahari S.K.; Mishra A.K.; "Anthelmentic Activities of Roots of CocusNucifera and Aerial Parts of Jasminum multiforum"; Asian journal of chemistry; 2007; 19(7):50895092.

17. Janssen A.M.;Sheffer J.J.C.;Svendsen B.; “Antimicrobial activity of essential oils: A 1976-1985 literature review", Aspects on the test methods, Plant Medica, 1987; 53:395-508.

18. Seyydnejad S.M.; Niknejad M.; Darabpoor I.; Motamedi H.; "Antibacterial Activity of Hydroalcoholic Extract of Callistemon Citrinus and Albizia Lebbeck", American J. of App. Sci. 2010; 7(1):13-16.

19. Ghatage S.L.; Navale S.S., Mujawar N.K., Patil S.; "Antimicrobial Screening”; Indian Journal of Drugs,2014; 2(3):84-88 